\title{
Comparison of Electro Ejaculator and Artificial Vagina on Semen Collection from South African Indigenous Goat Following Assessment by Computer Aided Sperm Analysis
}

\author{
Malebogo Audrey Bopape ${ }^{1,2}$, Khoboso Christina Lehloenya3 ${ }^{3}$ Tlou Caswell Chokoe", \\ Tshimangadzo Lucky Nedambale ${ }^{1,2,5,6^{*}}$ \\ ${ }^{1}$ Department of Animal Sciences, Tshwane University of Technology, Pretoria, South Africa \\ ${ }^{2}$ Germplasm Conservation and Reproductive Biotechnologies, Agricultural Research Council Animal Production \\ Institute, Pretoria, South Africa \\ ${ }^{3}$ Department of Animal \& Wildlife Sciences, University of Pretoria, Hatfield, South Africa \\ ${ }^{4}$ Farm Animal Genetic Resource, Department of Agriculture Forestry and Fisheries, Pretoria, South Africa \\ ${ }^{5}$ Department of Animal, Wildlife \& Grassland Sciences, University of Free State, Bloemfontein, South Africa \\ ${ }^{6}$ School of Agriculture, University of Venda, Thohoyandou, South Africa \\ Email: ${ }^{*}$ lucky@arc.agric.za
}

Received 10 March 2015; accepted 21 April 2015; published 27 April 2015

Copyright (C) 2015 by authors and Scientific Research Publishing Inc.

This work is licensed under the Creative Commons Attribution International License (CC BY).

http://creativecommons.org/licenses/by/4.0/

c) (i) Open Access

\section{Abstract}

South African indigenous bucks are raised under extensive conditions and are more likely to reject artificial vagina (AV) due to their limited contact with human beings, as they are less handled. The purpose of the study was to compare goat semen collection techniques used for goats based on semen traits of South African indigenous bucks during the natural breeding season. A total of eight South African indigenous bucks were used, four bucks per semen collection technique due to their scarcity. Before semen collection with AV group, ten bucks were trained and exposed to AV. Semen was then collected from both groups over a period of six weeks per individual buck. Semen volume, $\mathrm{pH}$ and sperm concentration were evaluated immediately. The Computer Aided Sperm Analysis (CASA) assessed the sperm motility rates. Sperm morphology was evaluated using a fluorescence microscope with the aid of eosin-nigrosin staining. Analysis of variance was used to test the differences among the semen collection groups following assessment by CASA. Semen collected with EE resulted in higher semen volume $(1.1 \mathrm{~mL})$ compared with $\mathrm{AV}(0.5 \mathrm{~mL})$ technique.

"Corresponding author.

How to cite this paper: Bopape, M.A., Lehloenya, K.C., Chokoe, T.C. and Nedambale, T.L. (2015) Comparison of Electro Ejaculator and Artificial Vagina on Semen Collection from South African Indigenous Goat Following Assessment by Computer Aided Sperm Analysis. Open Journal of Animal Sciences, 5, 210-218. http://dx.doi.org/10.4236/ojas.2015.52023 
However, AV technique resulted in higher total sperm motility and rapid movement $(91.9 \%$ and 48.7\%), live sperm (72\%) and sperm concentration $\left(635.6 \times 10^{6} \mathrm{sperm} / \mathrm{mL}\right)$ compared with EE $\left(86.3 \%\right.$ and $30.4 \%$; $69 \%$ and $463.7 \times 10^{6} \mathrm{sperm} / \mathrm{mL}$, respectively). There were no significant differences observed in $\mathrm{pH}$ and sperm morphology characteristics between two semen collection techniques. Moreover, EE had higher sperm moving in a progressive (53.6\%) and medium rate compared with AV (41.1\% and $21.9 \%)$ technique. It was concluded that the AV yielded higher total sperm motility rate, sperm concentration and rapid sperm movement compared with EE. Therefore, AV was more suitable for semen collection of South African indigenous bucks, even though training was problematic to such indigenous bucks.

\section{Keywords}

Artificial Vagina, Electro-Ejaculation, Sperm Motility, CASA

\section{Introduction}

South African indigenous goats are disease tolerant and able to survive better on harsh conditions such as extreme temperatures and poor vegetation [1]. These goats are also known for being non-selective browsers [2]. It is hypothesized that these goats can be used for breeding programs to transfer their hardiness to diseases and performing under poor conditions and nutrition. It is, therefore, important to include South African indigenous bucks in breeding objectives during this time of climatic change and when animals are resistant to antibiotics to transfer the valuable genetic characteristics. However, these goats are under a threat of extinction, which is rare to find without a across bred, and very little information on their reproductive status is recognized. Therefore, endangered indigenous goats' genetic materials must be preserved by conservation methods. However, the first step for the creation of a sperm cryobank is the use of an effective method for the collection of the ejaculates. For domestic males, the artificial vagina (AV) procedure is the preferred method [3] [4]. Consequently, AV technique requires a preliminary training period [5]. Another method of semen collection is the electro- ejaculator (EE) that involves an alternative when males are not trained to AV or for wild species. It is also a viable method of repeatedly collecting ejaculates from individual specimen without causing death [6]. Each of these semen collection techniques has advantages and disadvantages.

The collection of semen using AV is considered humane compared with EE, because it is almost similar to natural service and is the most hygienic technique [5]. However, the AV technique requires training of the bucks in the presence of a doe on heat [7] in contrast to the EE technique. Advantages of each technique have been reported, but differing depending on the objectives and conditions for semen collection. Previous studies show that the EE technique resulted in higher sperm motility rates and semen volume compared with the AV technique [8]-[10]. In contrast, the AV resulted in higher sperm concentration and lower abnormal sperm than the EE [4] [9] [11]. According to [8], the EE has been a preferred technique for semen collection compared with the AV, as it allows for semen collection from animals that reject the AV or animals with leg injuries which cannot mate. However, the EE technique has been described as a stressful technique indicated by different behavioural patterns such as vocalizing, struggling, lying down or the animal displaying strong muscular contractions [12]-[15]. Currently, the animal welfare has expressed anxiety concerning the use of the EE as a semen collection technique. However, indigenous male bucks are raised under extensive conditions and are more likely to reject the AV for semen collection, due to their limited contact with human beings. Therefore, the EE technique could be used as an alternative technique for semen collection under such conditions. Moreover, sperm cells characteristics of South African indigenous goats have not been assessed by computer aided sperm analysis (CASA). However, effects of semen collection technique can affect semen quality. Computer aided sperm analysis has been used and it has been reported to give objective and accurate results, and avoid technician errors compared with a subjective method [16].

Computer-assisted semen analysis provides objective and reproducible data on a number of sperm motion parameters and it should enhance the value of motility assessment to fertility prognosis. In recent years, there has been an increase in the use of these systems to evaluate semen quality [17] [18], resulting in high correlations 
among several CASA motility parameters and the in vivo fertility of sperm from different species in horses [19], in boar [20], and in bulls [21]. Marco-Jimenez et al. [8] documented that different physiological responses for attempted recovery were observed only when EE was used ( $80 \%$ efficiency versus $100 \%$ for AV). Moreover, [11] reported that sperm collected with AV was more resistant to cold shock than with EE. There is limited information comparing semen collection techniques on South African indigenous bucks. Therefore, the aim of this study was to compare semen collection techniques (AV or EE) effects on South African indigenous bucks' semen characteristics analysed by CASA.

\section{Materials and Methods}

The procedures for conducting this study were approved by the Animal Ethical Committee of the Agricultural Research Council, Animal Production Institute (APIEC2011/038) and Tshwane University of Technology (AREC2011/11/005).

\subsection{Study Area}

The study was conducted at the Agricultural Research Council Irene (small stock unit). The area is located at 25 53'59.6" South latitude and 28 12'51.6" East longitudes in Pretoria, South Africa. The area is situated in the Highveld, at an altitude of $1525 \mathrm{~m}$ above sea level. The weather conditions ranges from hot days and cool night in summer $\left(17.5^{\circ} \mathrm{C}\right.$ to $\left.32^{\circ} \mathrm{C}\right)$ to moderate winter days with very cold nights $\left(1^{\circ} \mathrm{C}\right.$ to $\left.17^{\circ} \mathrm{C}\right)[22]$.

\subsection{Animals and Management}

Twenty South African indigenous bucks were selected for two semen collection techniques (artificial vagina and electro-ejaculator). However, eight South African indigenous bucks were used for semen collection during the natural breeding season (autumn, 2012). Twelve bucks were excluded from the trial due to the reason that they did not respond to training for semen collection for four weeks using the AV technique. All the experimental bucks were allocated into two treatment groups (AV: $n=4$ and EE: $n=4)$ balanced with age $(1-2$ years) and weight $(25.0-45.0 \mathrm{~kg})$. The bucks grazed on kikuyu grass pastures and supplemented with lucerne and protein lick. Water was provided ad libitum throughout the experiment.

\subsection{Semen Collection and Evaluation}

Semen was collected from each group once a week for a period of six weeks during the natural breeding season (Autumn-February to April). For semen collection with AV, 10 bucks were trained for a period of 4 weeks in the presence of a doe showing heat before the onset of the study. Only four bucks responded, and were used for AV semen collection technique. For semen collection with EE, bucks were not trained for semen collection and the rectal probe of 3 - 5 volts was inserted through the rectum for electric stimulation. Following semen collection with either of the two methods, semen samples were kept in a thermoflask at $37^{\circ} \mathrm{C}$ and transported to the laboratory for evaluation within 1 hour after collection [23]. In the laboratory, semen samples were evaluated macroscopically for semen volume, $\mathrm{pH}$ and sperm concentration and microscopically for sperm motility, morphology and viability.

\subsubsection{Macroscopic Semen Evaluation}

Macroscopic semen evaluation included all evaluations performed with a naked eye such as semen colour, volume and $\mathrm{pH}$.

\section{1) Semen Volume}

The semen collected using AV was measured by recording the value on graduated semen collecting tube before being transferred into the $15 \mathrm{~mL}$ graduated Falcon tube. The measurement of semen collected by means of EE was also measured by reading the value on $15 \mathrm{~mL}$ graduated Falcon tubes (Minitube ${ }^{\circledR}$, South Africa). All the semen samples were labelled and then placed in a thermoflask at $37^{\circ} \mathrm{C}$ immediately after collection [23].

\section{2) Semen pH}

The semen $\mathrm{pH}$ was determined using a $\mathrm{pH}$ meter [(HANNA instruments ${ }^{\circledR}$, South Africa) (Pty) (Ltd.)] which was calibrated for bucks. The electrode was rinsed with sterile water and wiped with a sterile paper towel 
[(Transfarm ${ }^{\circledR}$, South Africa) (Pty) (Ltd.)] and then dipped into the semen sample for $\mathrm{pH}$ evaluation. Before the next semen sample was evaluated, the electrode was sprayed with 70\% Ethanol [(Sigma-Aldrich, South Africa) (Pty) (Ltd.)]. The pH value of each semen sample was recorded.

\subsubsection{Microscopic Semen Evaluation}

Microscopic semen evaluation included all evaluations which can be performed with a microscope such as sperm concentration, motility, viability and morphology.

\section{1) Sperm Concentration}

The sperm concentration was determined using spectrophotometer (Jenway 6310, Bibby Scientific, England) using the following formula (Dilution factor $(201) \times[25.97 \times($ Absorbance) -0.30$]$ for buck sperm concentration. A total amount of $3 \mathrm{~mL}\left(2.9 \%\right.$ of Sodium citrate) was placed in a microcuvette (HemoCue $\mathrm{AB}^{\circledR}$, Angelholm, Sweden) and calibrated using a spectrophotometer for 30 seconds. After calibration, Sodium citrate was removed from the spectrophotometer. Thereafter, $15 \mu \mathrm{L}$ of fresh undiluted buck semen was pipetted into a microcuvette and then placed back in the spectrophotometer. The reading was recorded when the absorbance number stops. Thereafter, spectrophotometer formula was used to calculate the sperm concentration for all samples. The buck sperm concentration was recorded as $\left(\times 10^{6} \mathrm{sperm} / \mathrm{mL}\right)$.

\section{2) Sperm Motility}

Sperm motility was evaluated using a CASA system, Sperm Class Analyzer ${ }^{\circledR}$ [SCA] 5.0 (Microscopic, S.L, Barcelona, Spain). The sperm washing solution (Brackett and Oliphant medium) was warmed to $37^{\circ} \mathrm{C}$ on a warm plate before being added to each semen sample. A total of $500 \mu \mathrm{L}$ of Brackett and Oliphant medium was diluted with $10 \mu \mathrm{L}$ of each semen sample to perform sperm swim up technique according to Matshaba [23]. Thereafter, $5 \mu \mathrm{L}$ of semen extended with Brackett and Oliphant medium was placed on a microscope slide (Thermo Scientific Menzelgläser, Germany) and covered with a microscope cover slip $(22 \times 22 \mathrm{~mm}$, Menzelgläser, Germany) and evaluated at $0,3,24,48$ and $72 \mathrm{~h}$ under $\times 10$ (Nikon, China) magnification of the CASA. The sperm motility characteristics (percentage of total, progressive, non-progressive static, slow, medium and rapid) were recorded and the Sperm Class Analyzer ${ }^{\circledR}$ settings are shown in Table 1.

\section{3) Sperm Morphology}

The microscopic evaluation of sperm morphology and viability is shown in Figure 1. The sperm morphological abnormalities (sperm with coiled midpiece or looped tail, double headed or tail) were determined using

\begin{tabular}{cc} 
Table 1. Sperm Class Analyzer & ${ }^{\mathbb{B}}$ \\
sperm motility characteristics. & settings used to analyse \\
\hline Parameter & Settings \\
\hline Contrast & 169 \\
Brightness & 470 \\
Image & 50 \\
Optic & Ph- \\
Chamber & Cover slide \\
Scale & $10 \times$ \\
Particle size $\left(\mu \mathrm{m}^{2}\right)$ & $5<70$ \\
Slow $(\mu \mathrm{m} / \mathrm{s})$ & $<50$ \\
Medium $(\mu \mathrm{m} / \mathrm{s})$ & $<100$ \\
Rapid $(\mu \mathrm{m} / \mathrm{s})$ & $<120$ \\
Progressivity $(\%)$ & $50 \%$ of straightness \\
Circular $(\%)$ & $50 \%$ of linearity \\
Connectivity & 11 \\
Number of images & 30 \\
\hline
\end{tabular}




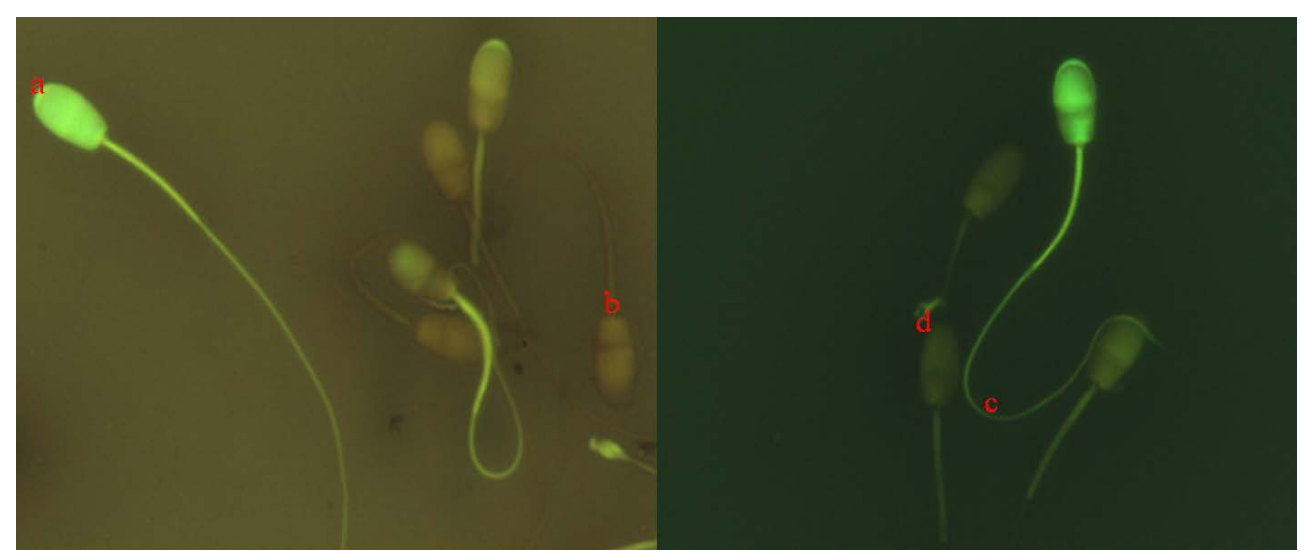

Figure 1. Stained indigenous buck sperm with eosin-nigrosin, $a=$ live normal sperm; $b=$ dead; $c=$ bent midpiece; $d=$ coiled tail. The $60 \times$ magnification of the fluorescent microscope was used for evaluating sperm morphology and viability

eosin/nigrosin staining (Onderstepoort Faculty of Veterinary Sciences' Pharmacy, South Africa) [23]. Sperm morphology and viability were evaluated using eosin-nigrosin staining. The dilution rate for staining was 1:4 eosin-nigrosin ( $5 \mu \mathrm{L}$ of raw semen and $20 \mu \mathrm{L}$ eosin-nigrosin staining). The composition of eosin-nigrosin (eosin $1.67 \mathrm{~g}$ and sodium citrate $2.9 \mathrm{~g}$ dissolved in $100 \mathrm{~mL}$ of sterile water) (nigrosin $100 \mathrm{~g} / \mathrm{L}$ and formalin [(SigmaAldrich, South Africa) (Pty) (Ltd.)] $5 \mathrm{~mL} / \mathrm{L}$ dissolved in sterile water). The raw and fresh diluted semen samples were placed on the slide. The second slide was used to smear semen across the surface of the first slide and allowed to dry at room temperature for approximately $45-60 \mathrm{~min}$ before evaluation. The slides were placed on a microscope table and a drop of immersion oil was placed on the slide to evaluate abnormal sperm using a fluorescent microscope (Olympus Corporation BX 51FT, Tokyo, Japan) under $\times 100$ magnification at $0,3,24,48$ and $72 \mathrm{~h}$.

\section{4) Sperm Viability}

Live normal and dead sperm were determined using eosin/nigrosin staining [23]. The dilution rate for staining was 1:4 eosin-nigrosin ( $5 \mu \mathrm{L}$ of raw semen and $20 \mu \mathrm{L}$ eosin-nigrosin staining). The second slide was used to smear semen across the surface of the first slide and allowed to dry at room temperature for approximately 45 $60 \mathrm{~min}$ before evaluation [23]. The slides were placed on a microscope table and a drop of immersion oil was placed on the slide to evaluate live normal or dead, sperm under a fluorescent microscope (Olympus Corporation BX 51FT, Tokyo, Japan) under $\times 100$ magnification at $0,3,24,48$ and $72 \mathrm{~h}$. The live normal sperm will fluorescent and dead sperm had brown or dark in colour as it absorbed eosin-nigrosin staining.

\subsection{Statistical Analysis}

Data collected from macroscopic and microscopic semen characteristics was analysed with analysis of variance (ANOVA) using Stata ${ }^{\circledR}$ V12 statistical software to test the differences between the treatments. Treatment means were separated using Fisher's protected t-test at the significant level of $\mathrm{P}<0.05$. The data expressed as mean \pm SD.

\section{Results and Discussion}

The semen characteristics following semen collection with the AV or EE are indicated in Table 2. Semen collected with the EE had $(\mathrm{P}<0.05)$ higher semen volume and total sperm motility compared to the AV technique. There were no significant differences on semen $\mathrm{pH}$ between the two semen collection techniques. However, the AV resulted in higher sperm concentration than the EE technique. The AV resulted in higher $(\mathrm{P}<0.05)$ total and rapid sperm motility compared to the EE technique. The EE on the other hand had $(\mathrm{P}<0.05)$ higher progressive, medium, slow and static sperm motility rates than AV technique.

Table 3 is presenting the results comparing the two semen collection techniques on sperm morphology and Figure 1 depicts the stained buck sperm with eosin-nigrosin. The EE semen collection technique resulted in higher live and normal sperm than the AV. However, there were no significant differences observed between the 
Table 2. Comparison of semen collection techniques on South African indigenous buck semen characteristics (mean $\pm \mathrm{SD}$ ).

\begin{tabular}{ccc}
\hline \multirow{2}{*}{ Semen characteristics } & \multicolumn{2}{c}{ Semen collection techniques } \\
\cline { 2 - 3 } Volume $(\mathrm{mL})$ & $0.5 \pm 0.3^{\mathrm{a}}$ & EE \\
Semen $\mathrm{pH}$ & $7.2 \pm 0.4^{\mathrm{a}}$ & $6.1 \pm 0.3^{\mathrm{b}}$ \\
Sperm concentration $\left(\times 10^{6} / \mathrm{mL}\right)$ & $635.6 \pm 111.7^{\mathrm{a}}$ & $463.7 \pm 156.0^{\mathrm{b}}$ \\
Sperm motility $(\%)$ & & \\
Total motility & $91.7 \pm 4.7^{\mathrm{a}}$ & $86.3 \pm 6.9^{\mathrm{b}}$ \\
Progressive & $41.1 \pm 8.2^{\mathrm{a}}$ & $53.6 \pm 9.3^{\mathrm{b}}$ \\
Non progressive & $50.5 \pm 8.3^{\mathrm{a}}$ & $32.7 \pm 11.2^{\mathrm{b}}$ \\
Rapid & $48.7 \pm 14.7^{\mathrm{a}}$ & $30.4 \pm 12.0^{\mathrm{b}}$ \\
Medium & $21.9 \pm 12.2^{\mathrm{a}}$ & $34.6 \pm 14.6^{\mathrm{b}}$ \\
Slow & $15.3 \pm 8.9^{\mathrm{a}}$ & $26.7 \pm 7.4^{\mathrm{b}}$ \\
Static & $8.3 \pm 4.7^{\mathrm{a}}$ & $13.8 \pm 6.9^{\mathrm{b}}$ \\
\hline
\end{tabular}

a,b values with different superscripts within rows differ significantly at $\mathrm{P}<0.05 ; \mathrm{AV}=$ artificial vagina; $\mathrm{EE}=$ electro-ejaculator.

Table 3. Comparison of semen collection techniques on South African indigenous buck sperm morphology (mean $\pm \mathrm{SD})$.

\begin{tabular}{ccc}
\hline & \multicolumn{2}{c}{ Semen collection techniques } \\
Sperm morphology $(\%)$ & AV & EE \\
\cline { 2 - 3 } Live & $72.0 \pm 21.0^{\mathrm{a}}$ & $69.0 \pm 17.8^{\mathrm{b}}$ \\
Dead & $30.5 \pm 12.8^{\mathrm{a}}$ & $35.2 \pm 6.8^{\mathrm{b}}$ \\
& Live sperm abnormalities & \\
Head & $4.2 \pm 3.7^{\mathrm{a}}$ & $6.8 \pm 4.5^{\mathrm{a}}$ \\
Mid-piece & $3.8 \pm 2.8^{\mathrm{a}}$ & $6.8 \pm 5.3^{\mathrm{a}}$ \\
Tail & $2.3 \pm 1.7^{\mathrm{a}}$ & $2.3 \pm 1.6^{\mathrm{a}}$ \\
\hline a,b values with different superscripts within rows differ significantly at $\mathrm{P}<0.05 ; \mathrm{AV}^{\mathrm{a}}=$ artifi- \\
cial vagina; EE $=$ electro-ejaculator.
\end{tabular}

semen collection techniques on sperm abnormalities (head, midpiece and tail). The EE resulted in higher (P $<$ 0.05 ) live and normal sperm than the AV technique. The study clearly demonstrated that semen collection from indigenous bucks with EE resulted in higher semen volume as compared to AV technique. The findings are in line with the results reported by [22] who indicated that higher semen volume $(1.77 \pm 0.3 \mathrm{~mL})$ was obtained from South African indigenous bucks when EE was used. However, these findings contradict to the results obtained by [24] [25] who reported lower semen volume of $0.8 \pm 0.1 \mathrm{~mL}$ when similar goat breed was used during the breeding season. The differences in semen volume obtained might be due to age of bucks used in the two studies. From the present study, the buck age ranged from 1 to 2 years. While in the study of [26], the semen was collected from 2 to 8 years. This observation clearly shows that semen volume of buck increases with age. The semen volume $0.5 \pm 0.3 \mathrm{~mL}$ obtained when the AV was used is lower when compared with the results obtained by [20] $(1.4 \pm 0.2 \mathrm{~mL})$, suggesting breed effect [27]. It must be emphasized that buck semen volume values obtained in this study are according to the acceptable ranges $(0.7$ to $2.2 \mathrm{~mL})$ for $\mathrm{EE}$ and $(0.5$ to $1.0 \mathrm{~mL})$ for 
buck semen collected with AV.

The semen $\mathrm{pH}$ obtained in this study when using AV $(7.2 \pm 0.4)$ was in line with the results obtained by [23] $(7.5 \pm 0.2)$. This semen $\mathrm{pH}$ is also acceptable, as buck semen $\mathrm{pH}$ usually ranges from 7.0 to 7.8 [28]. However, the semen $\mathrm{pH}$ for the EE technique $(6.9 \pm 0.3)$ was slightly acidic and the results are comparable to the results obtained by [29] (6.7 \pm 0.26$)$ in West African Dwarf goat breed. The semen $\mathrm{pH}$ obtained by [25] (6.1 \pm 0.2$)$ was even more acidic suggesting that, the EE technique leads to acidic buck semen and this might have a negative impact on fertility. The acidic semen gives an indication of excessive accessory glands secretion due to electrical stimulation in the rectum of the buck [14] [26] [30]. The excessive accessory glands are responsible for the buffering capacity of semen [30]. Latif et al. [31] also reported that in an acidic $\mathrm{pH}$ environment, the motility of sperm is affected, probably due to a change in the metabolic activity and a disturbance in the cellular respiration of the sperm.

The sperm concentration $\left(635.6 \pm 111.7 \times 10^{6} \mathrm{sperm} / \mathrm{mL}\right)$ reported from this study was comparable to the results reported by [15] $\left(681.7 \pm 74.6 \times 10^{6} / \mathrm{mL}\right)$ when the AV technique was used during the breeding season. Whereas, the sperm concentration obtained in this study when the EE $\left(463.7 \pm 156.0 \times 10^{6} \mathrm{sperm} / \mathrm{mL}\right)$ was used is higher when compared to several studies [23] [32] $\left(126.5 \pm 73.2 \times 10^{6} ; 115.9 \pm 11.3 \times 10^{6} \mathrm{sperm} / \mathrm{mL}\right.$, respectively) with semen collected during the natural breeding season. These differences might be due to breed difference or methods used for sperm concentration evaluation.

The sperm motility obtained in the current study was $86.3 \%$ and this is in agreement with previous reports [8] [26] when the EE technique was used, but contradictory to the results obtained by [33] (69.4\%). These differences emphasize the effect of breed and season of goat semen collection. However, the sperm motility (91.7\%) obtained in this study for AV was significantly higher to the findings of [23]. The results of live normal sperm and abnormalities obtained in this study are similar to other studies [23] [27]. However, the best semen collection technique is AV because it yielded higher total sperm motility, rapid sperm movement and live normal sperm. Consequently, the bucks are raised under extensive conditions and are more likely to reject AV due to their limited contact with human beings.

\section{Conclusion}

The artificial vagina technique resulted in higher sperm concentration, motility and live normal sperm, compared with the electro ejaculator technique. The results of the present study suggested that the success of the conservation of South African indigenous goats' semen depended on the semen collection technique. Therefore, the AV seems to be the most suitable technique for collecting semen of the South African indigenous bucks, although the bucks are raised under extensive conditions and are more likely to reject AV due to their limited contact with humans.

\section{Acknowledgements}

The author would like to thank Germplasm Conservation and Reproductive Biotechnologies (GCRB) staff for the assistance, Agricultural Research Council (ARC), Professional Development Program (PDP) scholarship (3014MA), National Research Foundation (NRF) and Department of Agriculture Forestry and Fisheries (DAFF) for the financial assistance.

\section{References}

[1] Donkin, E.F. and Boyazoglu, P.A. (2000) Milk Production from Bucks for Household and Small-Scale Farmers in South Africa. University of Pretoria, Pretoria.

[2] Agricultural Research Council (2006) The Indigenous Buck Breeds of South Africa. http://www.arc.agric.za/home.asp?pid=2701

[3] Leboeuf, B., Restall, B. and Salamon, S. (2000) Production and Storage of Goat Semen for Artificial Insemination. Animal Reproduction Science, 62, 113-114. http://dx.doi.org/10.1016/S0378-4320(00)00156-1

[4] Jiménez-Rabadán, P., Ramón, M.,García-Álvarez, O., Maroto-Morales, A., Del Olmo, E., Pérez-Guzmán, M.D., Bisbal, A., Fernández-Santos, M.R., Garde, J.J. and Soler, A.J. (2012) Effect of Semen Collection Method (Artificial Vagina vs. Electroejaculation), Extender and Centrifugation on Post-Thaw Sperm Quality of Blanca-Celtibérica Buck Ejaculates. Animal Reproduction Science, 132, 88-95. http://dx.doi.org/10.1016/j.anireprosci.2012.04.005

[5] Wulster-Radcliffe, M.C., Williams, M.A., Stellflug, J.N. and Lewis, G.S. (2001) Technical Note: Artificial Vagina vs. 
a Vaginal Collection Vial for Collecting Semen from Rams. Journal of Animal Science, 79, 2964-2967.

[6] Santiago-Moreno, J., Coloma, M.A., Dorado, J., Pulido-Pastor, A., Gómez Guillamon,F., Salas-Vega, R., GómezBrunet, A. and López-Sebastián, A. (2009) Cryopreservation of Spanish Ibex (Capra pyrenaica) Sperm Obtained by Electro-Ejaculation Outside the Rutting Season. Theriogenology, 71, 1253-1260. http://dx.doi.org/10.1016/j.theriogenology.2008.12.019

[7] Palmer, C.W. (2005) Welfare Aspects of Theriogenology: Investigating Alternatives to Electro-Ejaculation of Bulls. Theriogenology, 65, 469-479. http://dx.doi.org/10.1016/j.theriogenology.2005.05.032

[8] Marco-Jiménez, F., Vincente, J.S. and Vludes-De-Castro, M.P. (2008) Seminal Plasma Composition from Ejaculates Collected by Artificial Vagina and Electro-Ejaculation in Guirra Ram. Reproduction in Domestic Animals, 43, 403-408. http://dx.doi.org/10.1111/j.1439-0531.2007.00923.x

[9] Batista, M., Niño, T., Alamo, D., Castro, N., Santana, M., González, F., Cabrera, F. and Gracia, A. (2009) Successful Artificial Insemination Using Semen Frozen and Stored by an Ultra Freezer in the Majorera Buck Breed. Theriogenology, 71, 1307-1315. http://dx.doi.org/10.1016/j.theriogenology.2008.12.024

[10] Udeh, I. and Oghenesode, B. (2011) Effect of Extender and Storage Conditions on the Motility of Buck Spermatozoa. International Journal of Animal and Veterinary Advances, 5, 282-286.

[11] Marco-Jiménez, F., Puchades, S., Vincente, J.S. and Vludes-De-Castro, M.P. (2005) Effect of Semen Collection Method on Pre- and Post-Thaw Guirra Ram Spermatozoa. Theriogenology, 64, 1756-1765. http://dx.doi.org/10.1016/j.theriogenology.2005.04.006

[12] Carter, P.D., Hamilton, P.A. and Duffy, J.H. (1990) Electro Ejaculation in Bucks. Australian Veterinary Journal, 67, 91-93. http://dx.doi.org/10.1111/j.1751-0813.1990.tb07712.x

[13] Mosure, W.L., Meyer, R.A., Gudmondson, J. and Barth, A.D. (1998) Evaluation of Possible Methods to Reduce Pain Associated with Electro Ejaculation in Bull. Canadian Veterinary Journal, 39, 504-506.

[14] Ortiz-de-Montellano, M., Galindo-Maldonado, F., Cavazos-Arizpe, E.O., Aguayo-Arceo, A.M., Torres-Acosta, J.F. and Orihuela, A. (2007) Effect of Electro-Ejaculation on the Serum Cortisol Response of Criollo Bucks (Capra hircus). Small Ruminant Research, 69, 228-231. http://dx.doi.org/10.1016/j.smallrumres.2005.12.025

[15] Orihuela, A., Aguire, V., Hernandez, C., Flores-Perez, I. and Vazquez, R. (2009) Breaking down the Effect of Electro-Ejaculation on the Serum Cortisol Response, Heart and Respiratory Rate in Hair Sheep (Ovis aries). Journal of Animal Veterinary Advances, 8, 1969-1972.

[16] Jane, E.J., William, R.B. and Dawn, W.B. (1996) Manual versus Computer-Automated Semen Analyses. Determination or the Working Range of a Computer-Automated Semen Analyzer. Fertility and Sterility, 65, 156-159.

[17] Mortimer, S.T. (2000) CASA-Practical Aspects. Journal of Andrology, 21, 515-524.

[18] Foote, R.H. (2003) Fertility Estimation: A Review of Past Experience and Future Prospects. Animal Reproduction Science, 75, 119-139. http://dx.doi.org/10.1016/S0378-4320(02)00233-6

[19] Wilhelm, K.M., Graham, J.K. and Squires, E.L. (1996) Comparison of the Fertility of Cryopreserved Stallion Spermatozoa with Sperm Motion Analyses, Flow Cytometric Evaluation, and Zona-Free Hamster Oocyte Penetration. Theriogenology, 46, 559-578. http://dx.doi.org/10.1016/0093-691X(96)00209-9

[20] Holt, C., Holt, W.V., Moore, H.D., Reed, H.C. and Curnock, R.M. (1997) Objectively Measured Boar Sperm Motility Parameters Correlate with the Outcomes of On-Farm Inseminations: Results of Two Fertility Trials. Journal of Andrology, 18, 312-323.

[21] Farrell, P.B., Presicce, G.A., Brockett, C.C. and Foote, R.H. (1998) Quantification of Bull Sperm Characteristics Measured by Computer-Assisted Sperm Analysis (CASA) and the Relationship to Fertility. Theriogenology, 49, 871879. http://dx.doi.org/10.1016/S0093-691X(98)00036-3

[22] Webb, E.C., Dombo, M.H. and Roets, M. (2004) Seasonal Variation in Semen Quality of Gorno Altai Cashmere Bucks and South African Indigenous Bucks. South African Journal of Animal Science, 34, 240-243.

[23] Matshaba, B. (2010) Characterization and Cryopreservation of South African Unimproved Indigenous Buck Semen. Master's Dissertation, University of Free State, Bloemfontein.

[24] Talebi, J., Souri, M., Moghaddam, A., Karimi, I. and Mirmahmoodi, M. (2009) Characteristics and Seasonal Variation in the Semen of Markhoz in Western Iran. Small Ruminant Research, 85, 18-22. http://dx.doi.org/10.1016/j.smallrumres.2009.06.017

[25] Ramukhithi, F.V. (2011) Characterisation and Cryopreservation of South African Unimproved Indigenous and Boer Buck Semen. Master's Dissertation, Tshwane University of Technology, Pretoria.

[26] Ramukhithi, F.V., Nedambale, T.L., Sutherland, B. and Lehloenya, K.C. (2011) Cryopreservation of South African Indigenous Buck Semen. African Journal of Biotechnology, 77, 17898-17902.

[27] Batista, M., Niño, T., Santana, M., Alamo, D., Castro, N., Reyes, R., González, F., Cabrera, F. and Gracia, A. (2011) 
Influence of the Preservation Temperature (37, 20, 4, $\left.-196^{\circ} \mathrm{C}\right)$. Reproduction in Domestic Animals, 46, $281-288$. http://dx.doi.org/10.1111/j.1439-0531.2010.01659.x

[28] Prins, G.S. (1999) Semen. In: Knobil, E. and Neill, J.D., Eds., Encyclopedia of Reproduction 4, Academic Press, San Diego, 360-367.

[29] Ngoula, F., Tebug, T.T., Kenfack, A., Defang, F.H., Tendokeng, F. and Pamo, T.E. (2012) Effect of Buck Age, Storage Duration, Storage Temperature and Diluents on Fresh West African Dwarf Semen. Journal of Reproduction and Infertility, 3, 58-66.

[30] Sundararaman, M.N., Kalatharan, J. and Edwin, M.J. (2007) Attempts to Achieve Semen Collection from Incapacitated Boars by Electro-Ejaculation. Journal of Animal Veterinary, 4, 244-246.

[31] Latif, A., Ijaz, A., Aleem, M. and Mahmud, A. (2005) Effect of Osmotic Pressure and pH on the Short-Term Storage and Fertility of Broiler Breeder Sperm. Pakistan Veterinary Journal, 25, 180-182.

[32] Oyeyemi, M.O., Akusu, M.O. and Ola-Davies, O.E. (2000) Effect of Successive Ejaculations on the Spermiogram of West African Dwarf Bucks (Capra hircus L.). Veterinarski Arhiv Journal, 70, 215-221.

[33] Nur, Z., Dogan, I., Gunay, U. and Soylu, M.K. (2005) Relationships between Sperm Membrane Integrity and Other Semen Quality Characteristics of the Semen of Saanen Bucks. Bulletin of Veterinary Institute in Pulawy, 49, 183-187. 